\title{
Sudden stress relaxation in compound semiconductor thin films triggered by secondary phase segregation
}

\author{
R. Mainz, ${ }^{*}$ H. Rodriguez-Alvarez, M. Klaus, D. Thomas, J. Lauche, A. Weber, M. D. \\ Heinemann, S. Brunken, D. Greiner, C. A. Kaufmann, T. Unold, H.-W. Schock, and C. Genzel \\ Helmholtz-Zentrum Berlin für Materialien und Energie GmbH, Hahn-Meitner-Platz 1, 14109 Berlin, Germany
}

\begin{abstract}
In polycrystalline compound semiconductor thin films, structural defects such as grain boundaries as well as lateral stress can form during film growth, which may deteriorate their electronic performance and mechanical stability. In $\mathrm{Cu}$-based chalcogenide semiconductors such as $\mathrm{Cu}(\mathrm{In}, \mathrm{Ga}) \mathrm{Se}_{2}$ or $\mathrm{Cu}_{2} \mathrm{ZnSn}(\mathrm{S}, \mathrm{Se})_{4}$, temporary $\mathrm{Cu}$ excess during film growth leads to improved microstructure such as a reduced grain boundary density, a strategy that has been used for decades for high-efficiency chalcopyrite thin film solar cells. However, the mechanisms responsible for the beneficial effect of $\mathrm{Cu}$-excess are yet not fully clarified. Here, we investigate the evolution of lateral stress, grain growth and $\mathrm{Cu}$-Se segregation during $\mathrm{Cu}$-Se deposition onto $\mathrm{Cu}$-poor $\mathrm{CuInSe} \mathrm{I}_{2}$. Real-time x-ray diffraction and fluorescence analysis with a double-detector setup reveals that sudden stress relaxation occurs shortly prior to $\mathrm{Cu}$-Se segregation at the surface and precisely coincides with domain growth and change of texture. Numerical reaction-diffusion modeling provides an explanation for the observed delay of $\mathrm{Cu}$-Se segregation. Our results show that partial recrystallization of the film can be already reached without the necessity of an overall $\mathrm{Cu}$-rich film composition and thus suggest a new synthesis route for the fabrication of high-quality chalcopyrite absorber films.
\end{abstract}

Co-evaporation of $\mathrm{Cu}(\mathrm{In}, \mathrm{Ga}) \mathrm{Se}_{2}$ (CIGSe) films - used as absorber layer in thin film solar cells with world record energy conversion efficiencies ${ }^{1,2}$ - features a puzzling peculiarity: For the final film, a Cu-poor composition $([\mathrm{Cu}] /([\mathrm{In}]+[\mathrm{Ga}])<1)$ is required to obtain highest efficiencies; however, during deposition, the film composition is changed from an initially $\mathrm{Cu}$-poor composition to an intermediate $\mathrm{Cu}$-rich composition and finally changed back to a Cu-poor composition. The composition modifications during film deposition are realized by varying the $\mathrm{Cu}$ and $\mathrm{In}+\mathrm{Ga}$ evaporation fluxes. Two crucial findings point out the importance of the $\mathrm{Cu}$-poor $\rightarrow \mathrm{Cu}$-rich transition: First, highest efficiencies are only achieved if an intermediate $\mathrm{Cu}$-rich film composition was reached during film deposition. ${ }^{3}$ Second, a three-stage process with a $\mathrm{Cu}$-poor $\rightarrow \mathrm{Cu}$-rich $\rightarrow \mathrm{Cu}$-poor sequence leads to higher efficiencies than a two-stage process with only a $\mathrm{Cu}$-rich $\rightarrow$ Cu-poor sequence. ${ }^{4-6}$ Thus, it seems that the key challenge in understanding the success of the three-stage process over the two stage-process is - besides the adjustment of an ideal Ga gradient - the identification of the reactions and their driving forces acting during the $\mathrm{Cu}$-poor $\rightarrow$ Cu-rich transition.

While the effect of the $\mathrm{Cu}$-poor $\rightarrow \mathrm{Cu}$-rich transition on structural and morphological changes in CIGSe films such as grain growth ${ }^{7-10}$ as well as on electronic properties of the material ${ }^{3,11}$ has been thoroughly investigated in the past decade, the physical mechanisms and driving forces of these changes are not fully understood. Reduction of grain boundary (GB) energies or defect densities were proposed as possible driving forces for grain growth $;^{7-9}$ however, no attention has so far been paid to the potential role of stress energy for the microstructural changes. In other thin film materials evolution of intrinsic stress and their interplay with grain growth has been studied intensely both experimentally ${ }^{12-14}$ and theoretically, ${ }^{15,16}$ due to its importance for the mechani- cal stability of thin films. Diffusion of ad-atoms into GBs can lead to formation of compressive stress during deposition of metal films, ${ }^{12,15}$ while in turn stress may drive out-diffusion via $\mathrm{GBs}^{12}$ or cause GB migration. ${ }^{13,16,17}$

In contrast to pure metal films, in compound semiconductor films, stress may form due to compositiondependent lattice parameters. In the case of $\mathrm{Cu}^{-}$ poor CIGSe, the lattice expands with increasing $\mathrm{Cu}$ concentration. ${ }^{18}$ Hence formation of compressive stress during $\mathrm{Cu}-\mathrm{Se}$ incorporation into the $\mathrm{Cu}$-poor film on a rigid substrate can be expected. The lack of studies of stress evolution during deposition of chalcopyrite compound semiconductor thin films is most likely due to the difficulty to detect stress changes by process interruptions in combination with standard ex situ methods, because the subtle changes of stress during film deposition at high temperatures may be obscured by thermal stress during sample cool down. An added difficulty with CIGSe is the In-Ga gradient, which additionally alters the lattice spacings and generally makes changes due to stress particularly hard to detect.

In this paper, we bridge this gap by combining in situ energy-dispersive $\mathrm{x}$-ray diffraction and fluorescence analysis (EDXRD/XRF) during thin film co-evaporation ${ }^{19}$ with a two-detector setup ${ }^{20}$ facilitating simultaneous real-time analysis of phase formation, microstructural evolution, residual stress, and elemental depth distributions. To rule out the potential influence of Ga diffusion on changes of lattice spacings, pure $\mathrm{CuInSe} \mathrm{S}_{2}$ without $\mathrm{Ga}$ is investigated. We show that relaxation of compressive residual stress precisely correlates with domain growth and texture changes and takes place shortly before $\mathrm{Cu}-$ Se starts to segregate at the surface. Our conclusion that film recrystallization propagates from the surface to the bottom of the film as the $\mathrm{CuInSe}_{2}$ layer becomes $\mathrm{Cu}$-saturated is quantitatively supported by a numerical reaction-diffusion model. Our findings suggest that 


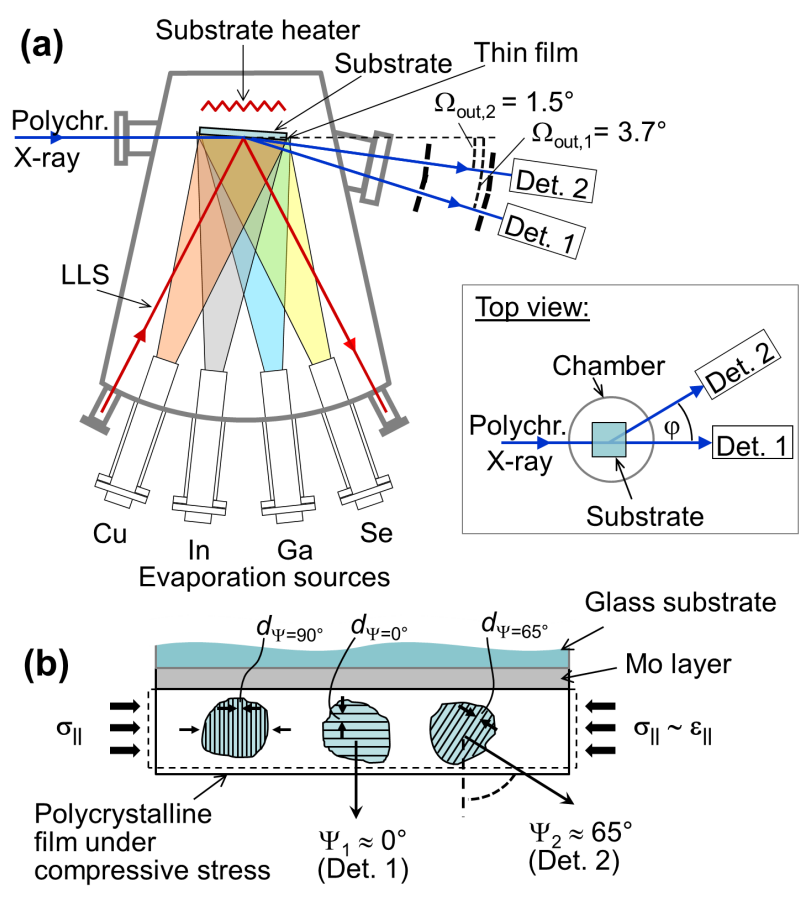

Figure 1. (a) Schematic drawing of the experimental realtime EDXRD/XRF setup for in-situ analysis of thin film coevaporation (LLS: laser light scattering). (b) Visualization of the orientations of lattice planes seen by the two detectors (Det. 1 and Det. 2).

partly recrystallized CIGSe films can be grown without a $\mathrm{Cu}$-rich stage - hence without the need for a final In-GaSe deposition stage to compensate $\mathrm{Cu}-\mathrm{Se}$ segregations, and hence conserving a surface of high-quality recrystallized CIGSe.

\section{EXPERIMENTAL}

$\mathrm{CuInSe}_{2}$ films were deposited by thermal evaporation onto Mo-coated soda-lime glass in an in situ coevaporation chamber tailor made for real-time x-ray analysis (Fig. 1a). The 1st stage of the three-stage process (In-Se deposition) was performed at a substrate temperature of $330{ }^{\circ} \mathrm{C}$, the 2 nd stage $(\mathrm{Cu}-\mathrm{Se})$ and 3 rd stage (In-Se) at $530{ }^{\circ} \mathrm{C}$.

Real-time analysis during co-evaporation by EDXRD/XRF was performed with polychromatic synchrotron radiation between 6 and $100 \mathrm{keV}$ at the EDDI beamline at BESSY II, equipped with two energydispersive $\mathrm{Ge}$ detectors. ${ }^{20}$ Both detectors recorded radiation from the same sample area with a size of approximately $1 \mathrm{~mm} \times 2.2 \mathrm{~mm}$. The geometries for the two detectors were chosen such that lattice spacings of planes nearly parallel ( $\Psi \approx 0^{\circ}$, detector 1 ) as well as tilted with respect to the sample surface $\left(\Psi \approx 65^{\circ}\right.$, detector 2) could be observed simultaneously (Fig. 1b). The diffraction angles $2 \theta_{1}=6.301^{\circ} \pm 0.002^{\circ}$ and $2 \theta_{2}=9.722^{\circ} \pm 0.002^{\circ}$ for detector 1 and 2 were calibrated with $99.99 \%$ purity gold powder. The angle between incident radiation and sample surface was $\Omega_{\text {in }}=2.62^{\circ}$ and the angle between diffracted radiation and sample surface was $\Omega_{\text {out,1 }}=3.68^{\circ}$ for detector 1 and $\Omega_{\text {out }, 2}=1.50^{\circ}$ for detector 2 . The position of the film was kept constant within the active volume during heating by monitoring the maximum intensity of the Mo-K $\alpha$ line coming from the Mo coating of the substrate. The instrumental diffraction line broadening was determined with $\mathrm{LaB}_{6}$ powder. We note that the diffraction and fluorescence signals for each detector come from the same active sample volume. Therefore, the uncertainty of the time correlation between the evolution of $\mathrm{Cu}-K \alpha$ intensity and the evolutions of strain, texture and domain growth is negligible. The photon energies of the diffraction signals were gained from the spectra by least-square peak fits with pseudo-Voigt profiles. Lattice plane spacings $d_{h k l}$ were calculated from the energy position $E_{h k l}$ of the diffraction signals by the energy dispersive Bragg equation $d_{h k l}=h c / 2 E_{h k l} \sin (\theta)$ (where $h$ is Planck's constant and $c$ the speed of light). Additionally, diffuse laser light scattering (LLS) at 635 $\mathrm{nm}$ wavelength, which is an established process control technique for three-stage co-evaporation, ${ }^{19,21}$ as well as direct light reflection at the same wavelength were measured simultaneously with EDXRD/XRF.

\section{RESULTS AND DISCUSSION}

It is known that during Cu-Se deposition in the 2nd stage of the three-stage co-evaporation process, $\mathrm{In}_{2} \mathrm{Se}_{3}$ sequentially transforms into $\gamma-\mathrm{CuIn}_{5} \mathrm{Se}_{8} \rightarrow \beta-\mathrm{CuIn}_{3} \mathrm{Se}_{5}$ $\rightarrow \alpha-\mathrm{CuInSe}_{2} \rightarrow \alpha-\mathrm{CuInSe}{ }_{2}+\mathrm{Cu}-\mathrm{Se} .{ }^{19}$ Fig. 2 shows the evolution of the $\mathrm{Cu}$-In-Se 112 diffraction signal, that can be attributed to $\beta$-CuIn ${ }_{3} \mathrm{Se}_{5}$ and $\alpha$-CuInSe 2 . The dots mark the peak position resulting from a peak fit for each spectrum. The continuous shift to lower energies corresponds to a continuous increase of the 112 lattice spacing with increasing $[\mathrm{Cu}] /[\mathrm{In}]$ ratio. The sudden shift to higher energies at around $51 \mathrm{~min}$. takes place close to the transition from $\mathrm{Cu}$-poor $([\mathrm{Cu}] /[\mathrm{In}]<1)$ to $\mathrm{Cu}$-rich $([\mathrm{Cu}] /[\mathrm{In}]>1)$ film composition. In the following, we investigate in detail the last part of the $\mathrm{Cu}$-Se deposition (marked by the vertical lines in Fig. 2) with the transformation from $\mathrm{Cu}$-poor $\alpha-\mathrm{CuInSe} \mathrm{S}_{2}$ to a $\mathrm{Cu}$-rich film composition.

\section{A. Evolution of Strain}

The evolution of lattice plane spacings of the $\mathrm{CuInSe}_{2}$ 112 planes parallel to the surface $\left(d_{112, \Psi \approx 0^{\circ}}\right.$, Det. 1$)$ resulting from the maxima of the peak fits shown in Fig. 2 as well as 112 planes tilted with respect to the surface $\left(d_{112, \Psi \approx 65^{\circ}}\right.$, Det. 2) are shown in Fig. 3a as a function of $\mathrm{Cu}$-Se deposition time. For both lattice plane orienta- 


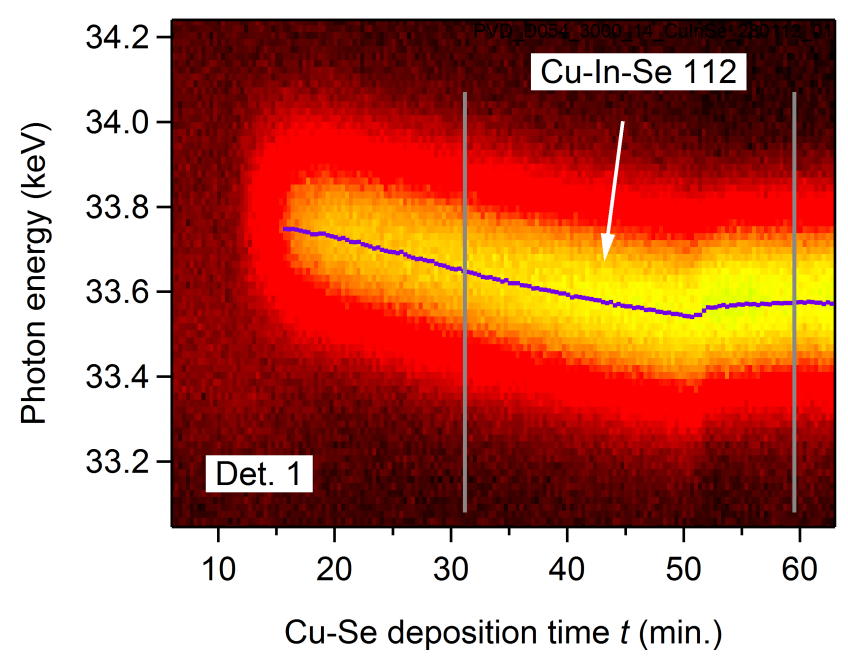

Figure 2. Color-coded real-time EDXRD data of the 112 reflection of the $\beta$ - and $\alpha$-Cu-In-Se phase during $\mathrm{Cu}$-Se deposition onto a In-Se film recorded by detector 1 (labeled Det. 1 in Fig. 1) under a diffraction angle of $2 \theta_{1}=6.301^{\circ}$. The dots mark the peak position resulting from a peak fit for each spectrum. The vertical lines mark the time interval that is investigated in detail in Fig. 3.

tions an increase of lattice spacing during $\mathrm{Cu}$ incorporation into the $\mathrm{Cu}$-poor film can be observed. However, a difference between the absolute values for $d_{112, \Psi \approx 0^{\circ}}$ and $d_{112, \Psi \approx 65^{\circ}}$ can bee clearly seen. This difference indicates a non-negligible macroscopic compressive stress present in the $\mathrm{Cu}$-poor $\mathrm{Cu}-\mathrm{In}$-Se film, which started to form at an earlier stage of $\mathrm{Cu}-\mathrm{Se}$ deposition (see also Fig. $\mathrm{S}^{22}$ ).

Remarkably, the continuous increase of the lattice spacings suddenly stops (vertical line A in Fig. 3) with a quick decrease of $d_{112, \Psi \approx 0^{\circ}}$ and a quick increase of $d_{112, \Psi \approx 65^{\circ}}$. These changes lead to a decreased lattice spacings difference $d_{112, \Psi \approx 0^{\circ}}-d_{112, \Psi \approx 65^{\circ}}$, which indicates relaxation of compressive stress. (Note that the error bars represent systematic uncertainties of the absolute values, not of the relative changes.) From the continuous evolution of the lattice spacings of Mo 110 (Fig. 3a), we can exclude that the observed lattice spacing changes are caused by measurement artifacts. Since diffraction signals at different energies and thus with different information depths show the same behavior as the ones presented in Fig. 3a, we can exclude that the changes of lattice spacings are caused by changes of compositional depth gradients (see Supplemental Material ${ }^{22}$, Fig. S2 and Table S1).

To ascertain that the decrease in lattice spacings difference can be attributed to relaxation of compressive stress, we show that this interpretation is consistent with basic equations of elasticity. In a film with biaxial plane stress the Poisson ratio $\nu$ relates the in-plane elastic strain $\varepsilon_{\|}=\left(d_{\Psi=90^{\circ}}-d_{\mathrm{r}}\right) / d_{\mathrm{r}}$ to the vertical strain $\varepsilon_{\perp}=\left(d_{\Psi=0^{\circ}}-d_{\mathrm{r}}\right) / d_{\mathrm{r}}$ (with $d_{\mathrm{r}}$ being the lattice spacing in the relaxed state - the notation $d_{r}$ is used here instead of $d_{0}$ to avoid confusion with $d_{\Psi=0^{\circ}}:^{23}$

$$
\varepsilon_{\perp}=-\frac{2 \nu}{1-\nu} \varepsilon_{\|}
$$

$\nu$ has only a weak dependence on temperature. Hence, by calculating $\nu$ from the real-time data and comparing it with room temperature values we can check if the changes of lattice spacings (Fig. 3a) are consistent with relaxation of stress. The in-plane strain $\varepsilon_{\|}$in Eq. (1) can be calculated for biaxial plane stress with rotational symmetry using the relation ${ }^{24}$

$$
\varepsilon_{\Psi}=\frac{d_{\Psi}-d_{\mathrm{r}}}{d_{\mathrm{r}}}=\varepsilon_{\|} \cdot \sin ^{2} \Psi+\varepsilon_{\perp} \cdot \cos ^{2} \Psi .
$$

Substituting Eq. (1) into Eq. (2), replacing $\varepsilon_{\Psi}$ and $\varepsilon_{\perp}$ by the differences in lattice spacings before and after the strain relaxation $\left(\Delta d=d_{\text {after }}-d_{\text {before }}\right)$, and resolving for $\nu$, we obtain ${ }^{22}$

$$
\nu=\frac{\sin ^{2} \Psi}{2\left(1-\frac{\Delta d_{\Psi}}{\Delta d_{0^{\circ}}}\right)-\sin ^{2} \Psi} .
$$

With $\Psi=65^{\circ}$ and with the differences between the lattice spacings before and after the relaxation for $\Delta d_{0^{\circ}}$ and $\Delta d_{65^{\circ}}$ extracted from Fig. 3a, we obtain the Poisson ratio $\nu \approx 0.3 \pm 0.07$ (see ${ }^{22}$ for details), which is consistent with literature data ${ }^{25}$ of $\nu=0.3$ for CIGSe. With Eqs. (1) and (2), and by inserting $\nu=0.3$ and the measured lattice spacings $d_{\Psi=0^{\circ}}$ and $d_{\Psi=65^{\circ}}$, we calculate the evolution of the relaxed lattice spacing $d_{\mathrm{r}}$ and the in-plane strain $\varepsilon_{\|}$, which are plotted in Figs. 3a and b (see Supplemental Material for details ${ }^{22}$ ). The fact that the evolution of the calculated relaxed lattice spacing $d_{\mathrm{r}}$ is continuous between the vertical dashed lines (Fig. 3a) confirms that the changes of the measured lattice spacings $d_{\Psi=0^{\circ}}$ and $d_{\Psi=65^{\circ}}$ can consistently be explained by stress relaxation during the transition from $\mathrm{Cu}$-poor to $\mathrm{Cu}$-rich composition.

\section{B. Correlation between strain relaxation and grain growth}

The initial formation of compressive strain can be understood by considering that incorporation of $\mathrm{Cu}$ expands the lattice of the $\mathrm{Cu}$-In-Se phases and that the film is deposited on a rigid substrate. The transition from $\mathrm{CuIn}_{3} \mathrm{Se}_{5}$ to $\mathrm{CuInSe}_{2}$ can take place purely by cation exchange ${ }^{26}$ within the fcc-type Se sublattice, accompanied by lattice expansion. ${ }^{18}$ Thus, formation of compressive stress is expected due to the rigid substrate. However, the observed maximum compressive strain of $-1.3 \cdot 10^{-3}$ (Fig. 3b) is lower than the maximum compressive strain expected for a lattice expansion corresponding to the increase of $d_{\mathrm{r}}$ seen in Fig. 3a, which is $\Delta \varepsilon_{\|}^{\max } \approx-5 \cdot 10^{-3}\left(\right.$ see $\left.\mathrm{SM}^{22}\right)$. The fact that the compressive strain does not exceed a value of $-1.3 \cdot 10^{-3}$ 

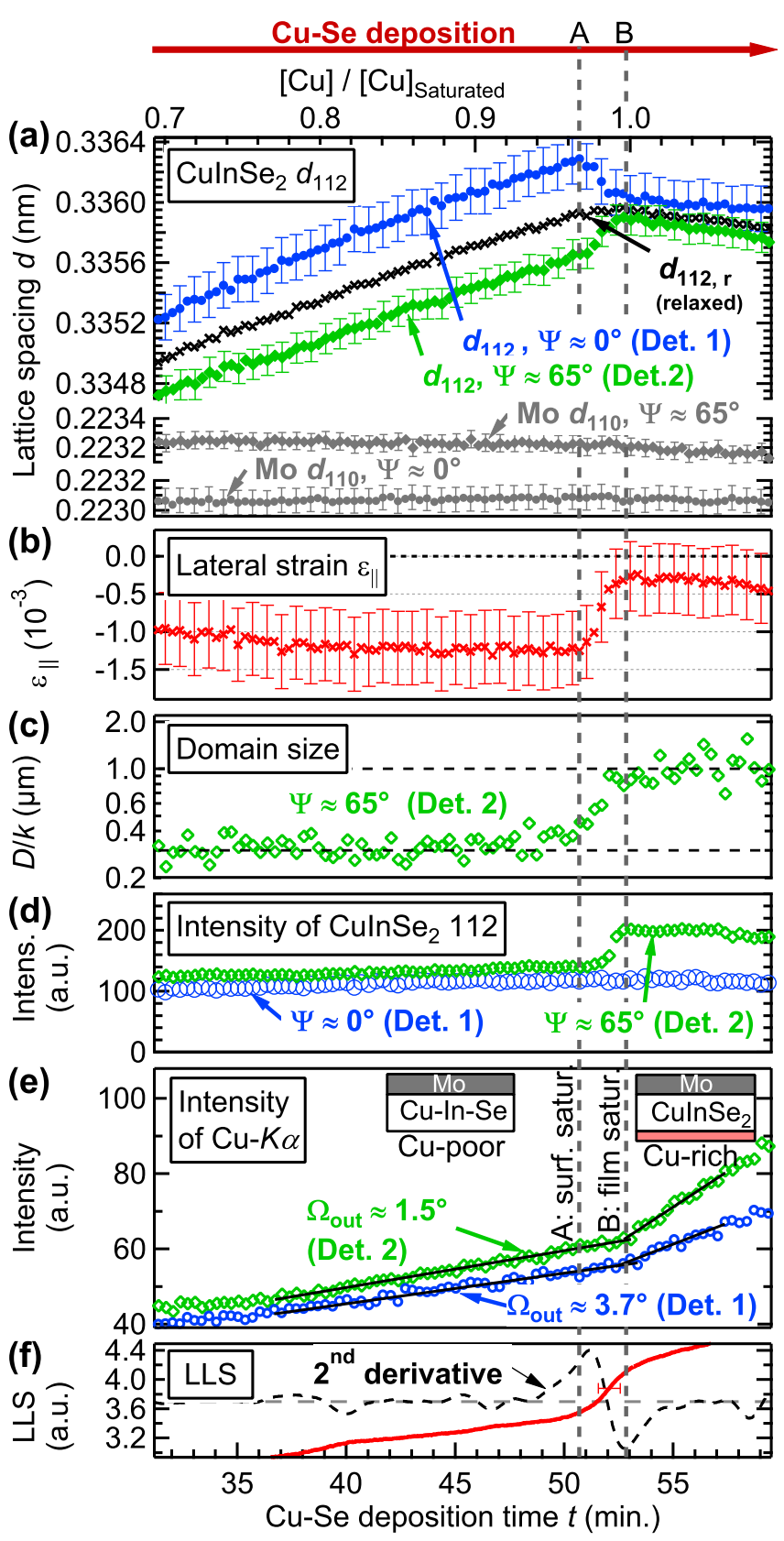

Figure 3. Real-time EDXRD/XRF and LLS data recorded during co-evaporation of $\mathrm{Cu}$-Se onto a $\mathrm{Cu}-\mathrm{In}$-Se film at the end of $2 \mathrm{nd}$ stage of the three-stage $\mathrm{CuInSe}_{2}$ synthesis process. (a) Lattice spacings of the $\mathrm{CuInSe}_{2} 112$ planes and Mo 110 planes oriented parallel (Det. 1) and tilted (Det. 2 ) to the substrate surface. $d_{\mathrm{r}}$ denotes relaxed lattice spacings calculated with $\nu=0.3$. (b) Calculated in-plane strain $\left(\varepsilon_{\|}=\left(d_{\Psi=90^{\circ}}-d_{\mathrm{r}}\right) / d_{\mathrm{r}}\right)$ in the $\mathrm{CuInSe}_{2}$ film. Error bars represent uncertainties of the absolute values. (c) Domain size extracted from the Cauchy width and (d) integral intensity extracted from the $\mathrm{CuInSe}_{2} 112$ signal. (e) Integral intensity of $\mathrm{Cu}-\mathrm{K} \alpha$ fluorescence signals measured with detector 1 and 2 under different exit angles $\Omega_{\text {out }}$. (f) Intensity of laser light scattering (LLS) at $635 \mathrm{~nm}$ wavelength and its $2 \mathrm{nd}$ derivative. suggests that at this strain level the yield strength of $\mathrm{Cu}$-poor $\mathrm{CuInSe}_{2}$ is reached and that further lattice expansion leads to plastic deformation instead of a further increase of elastic strain.

The sudden relaxation of stress precisely coincides with an increase of domain size of coherent scattering from approximately $0.3 \mu \mathrm{m}$ to around $1 \mu \mathrm{m}$ (Fig. 3c). The domain size, which is a lower limit for grain size, is calculated with the help of Scherrer's formula from the Cauchy contribution of the profile broadening of the $\mathrm{CuInSe}_{2} 112$ signal (Fig. S3 in $\mathrm{SM}^{22}$ ). Due to a reduced density at $\mathrm{GBs}^{27,28}$ grain growth, i.e. reduction of GB area, generally leads to a material densification. Hence reduction of compressive strain can be expected during grain growth, following the relation

$$
\varepsilon_{\|}=\varepsilon_{\|, 0}+\delta\left(1 / D_{0}-1 / D\right),
$$

where $\varepsilon_{\|, 0}$ is the initial in-plane strain, $D_{0}$ the initial grain size, and $\delta$ the effective GB width. ${ }^{17}$ Setting $D_{0}=0.3 \mu \mathrm{m}$ (which is the initial domain size determined from the diffraction line broadening) and with an effective GB width in the order of the atomic distances in the chalcopyrite structure $\delta=0.3 \mathrm{~nm}$, we obtain a maximum reduction of compressive in-plane strain during grain growth of $1 \cdot 10^{-3}$, which is close to the strain reduction observed in Fig. 3b. Hence independent of the driving forces leading to grain growth, the observed reduction of compressive strain can be expected during grain growth.

\section{Strain energy as driving force for grain growth}

Since strain reduction goes along with a reduction of strain energy, compressive strain - besides GB energy can act as additional driving force for grain growth. ${ }^{17}$ The driving force for grain growth in chalcopyrite thin films is commonly proposed to be the reduction of energy stored in the GBs. ${ }^{7-9}$ To judge whether compressive stress can play a significant role as additional driving force, we estimate and compare the energy decrease expected from reduction of GB area and the energy decrease expected from relaxation of the compressive in-plane stress.

The integral GB energy density as function of average grain diameter $D$ is $u_{\mathrm{b}} \approx 2 \gamma_{\mathrm{b}} / D$ (where $\gamma_{\mathrm{b}}$ is the GB energy per area). ${ }^{17}$ At an initial average grain size $D_{0}$ of $0.3 \mu \mathrm{m}$ and with $\gamma_{\mathrm{b}} \approx 0.1 \mathrm{~J} \mathrm{~m}^{-2},{ }^{29}$ we obtain a decrease of GB energy density during grain growth of

$$
\left.\frac{\mathrm{d} u_{\mathrm{b}}}{\mathrm{d} D}\right|_{D_{0}}=-2 \frac{\gamma_{\mathrm{b}}}{D_{0}^{2}} \approx-2 \cdot 10^{12} \frac{\mathrm{J}}{\mathrm{m}^{4}} .
$$

The strain energy density for biaxial in-plane strain per volume is ${ }^{17}$

$$
u_{\mathrm{s}}=E \varepsilon_{\|}^{2} /(1-\nu)=\widetilde{E} \varepsilon_{\|}^{2} .
$$

With Young's modulus $E=3 K(1-2 \nu)=90 \mathrm{GPa}$ (calculated from Ref. ${ }^{30}$ ), with $\nu=0.3$, and by inserting Eq. 
(4) with $\varepsilon_{\|, 0}=-1.3 \cdot 10^{-3}$, we obtain at $D_{0}$

$$
\left.\frac{\mathrm{d} u_{\mathrm{s}}}{\mathrm{d} D}\right|_{D_{0}}=\frac{2 \widetilde{E} \delta \varepsilon_{\|, 0}}{D_{0}^{2}} \approx-1 \cdot 10^{12} \frac{\mathrm{J}}{\mathrm{m}^{4}} .
$$

Hence, we find the decrease of strain energy and that of grain boundary energy during grain growth to be in the same order of magnitude, suggesting that relaxation of compressive stress acts as additional driving force for grain growth in $\mathrm{CuInSe}_{2}$. Further indication that strain plays a role for grain growth is provided by the evolution of the intensities of the diffraction signals (Fig. $3 d$ ): While the intensity from $\{112\}$ planes parallel to the surface (Det. 1) stays constant, the intensity from $\{112\}$ planes tilted by $65^{\circ}$ with respect to the surface (Det. 2) shows a strong increase during stress relaxation and domain growth. In normal isotropic grain growth where GB migration is purely driven by GB energy reduction, texture is preserved. ${ }^{17}$ In contrast, grain growth where grains with a specific orientation grow faster than others can be fostered by strain in materials with anisotropic strain modulus. Then, the biaxial modulus $\widetilde{E}_{h k l}$ for in-plane strain, and thus also the strain energy $u_{\mathrm{s}, h k l}=\widetilde{E}_{h k l} \varepsilon_{\|\|}^{2}$, depend on grain orientation. ${ }^{17}$ For CuInSe 2 , we obtain $\widetilde{E}_{001}=130 \mathrm{GPa}$ and $\widetilde{E}_{112}=83 \mathrm{GPa}$ (calculated from the stiffness constants in Ref. ${ }^{31}$ ). Hence in-plane strain can be expected to support the growth of grains with their $\{001\}$ planes parallel to the surface. Since the angle between $\{001\}$ planes and $\{112\}$ planes of around $55^{\circ}$ is close to the inclination angle of Det. 2 $\left(\approx 65^{\circ}\right)$, an increase of the 112 intensity in Det. 2 can be expected during growth of $\{001\}$ oriented grains as observed in Fig. 3d. We take the coincidence of stress relaxation, increase of domain size, and change of texture as justification for the usage of the term recrystallization $;^{32}$ we note, however, that different definitions of this term exist in the literature.

\section{Role of $\mathrm{Cu}$ saturation}

An important remaining question is, what causes the sudden onset of domain growth and stress relaxation. Presence of $\mathrm{Cu}$-Se has been proposed to facilitate an increased mobility of the cations at grain boundaries ${ }^{33}$ and it was shown experimentally both ex situ ${ }^{7}$ and in situ ${ }^{9}$ that the activation energy for grain growth is lowered at $\mathrm{Cu}$-rich compositions compared to $\mathrm{Cu}$-poor compositions. Therefore it seems reasonable to assume that domain growth and strain relaxation observed in Fig. 3 starts at the point where the film turns from $\mathrm{Cu}$-poor to $\mathrm{Cu}$-rich due to an increased grain boundary mobility.

However, at first sight we find a discrepancy to this picture. In our experiment, the simultaneously recorded $\mathrm{Cu}-\mathrm{K} \alpha$ fluorescence signals (Fig. 3e) provide real-time information about $\mathrm{Cu}$-Se segregation at the surface, which can be directly correlated with the observed strain relaxation, domain growth, and texture changes in Figs. 3b-d. The intensities of $\mathrm{Cu}-\mathrm{K} \alpha$ observed in detector 1 and 2 first slowly increase with increasing $\mathrm{Cu}$ content of the film up to the second vertical line (line B in Fig. 3e) and then abruptly become steeper. Numerical model calculations revealed that this steepening of the $\mathrm{Cu}-\mathrm{K} \alpha$ intensity can be explained by $\mathrm{Cu}_{2}$ Se segregation at the film surface with a constant growth rate,${ }^{19,34}$ which is consistent with recent observations by real-time ellipsometry. ${ }^{35}$ The steepening is more pronounced in detector 2 than in detector 1 , because detector 2 has a lower exit angle and hence a higher surface sensitivity than detector 1 .

The constant rate of $\mathrm{Cu}$-Se segregation at the surface beyond point $\mathrm{B}$ reveals that no additional $\mathrm{Cu}$ can be incorporated into the $\mathrm{Cu}-\mathrm{In}-\mathrm{Se}$ film after that point. We refer to this point as the point of $C u$ saturation of the film, which according to the $\mathrm{Cu}$-In-Se phase diagram can be expected to be close to the $\mathrm{CuInSe}_{2}$ stoichiometry $([\mathrm{Cu}] /[\mathrm{In}] \approx 1) .{ }^{36}$ Surprisingly, the recrystallization, i.e. stress relaxation, domain growth and texture change, takes place shortly before the $\mathrm{Cu}$-saturation of the film (Fig. 3b-e). Between the start of stress relaxation (A) and start of detectable $\mathrm{Cu}-\mathrm{Se}$ saturation (B) the $\mathrm{Cu}$ concentration of the film increases by about $4 \%$ (see top scale in Fig. 3). Consequently, during recrystallization between line $\mathrm{A}$ and line $\mathrm{B}$ the film was not yet fully $\mathrm{Cu}-$ saturated. Since, however, $\mathrm{Cu}$ diffusion into the film coupled to In diffusion out of the film - can be expected to be driven by a - possibly quite shallow - $\mathrm{Cu} / \mathrm{In}$ gradient, $\mathrm{Cu}$ saturation of the $\mathrm{CuInSe}_{2}$ phase should be reached first at the surface and subsequently propagate into the film until it reaches the bottom of the film. We conclude that $C u$ saturation at the surface is already reached at point $\mathrm{A}$, initiating recrystallization near the surface which subsequently propagates from the surface to the backside of the film until at point $\mathrm{B}$ the complete film is Cu-saturated.

In contrast to the $\mathrm{Cu}-\mathrm{K} \alpha$ fluorescence signal, laser light scattering (LLS) provides a signature of the recrystallization already at its onset at point $\mathrm{A}$, that is before $\mathrm{Cu}-\mathrm{Se}$ segregation is detected by $\mathrm{Cu}-\mathrm{K} \alpha$ (Fig. 3f). An increase in roughness can be excluded as origin for the LLS increase, since direct reflection also shows an intensity increase (Fig. $\mathrm{S} 4$ in $\mathrm{SM}^{22}$ ). However, since $\mathrm{Cu}_{2-\delta} \mathrm{Se}$ has a higher reflectivity than CISe ${ }^{37}$ the early rise in LLS might be caused by very small amounts of $\mathrm{Cu}_{2-\delta} \mathrm{Se}$ segregations that are too small to be detected by fluorescence.

\section{E. Numerical Reaction-Diffusion Modeling of $\mathrm{Cu}-\mathrm{Se}$ deposition}

To see whether the delay between the onset of the recrystallization and the onset of $\mathrm{Cu}-\mathrm{Se}$ segregation at the film surface can quantitatively be explained by an evolution of $\mathrm{Cu}$ saturation from the surface toward the back of the film, we perform 1-dimensional reaction diffusion modeling and compare the model results to the experi- 
Table I. Input parameters for the numerical reaction-diffusion modeling for a process temperature of $530{ }^{\circ} \mathrm{C}$. The relative $\mathrm{Cu}$ concentrations $[\mathrm{Cu}] /([\mathrm{Cu}]+[\mathrm{In}]+[\mathrm{Se}])$ give the minimum and maximum limits of the homogeneity range of each phase. The maximum relative $\mathrm{Cu}$ concentration of 0.2485 for the $\mathrm{Cu}$-saturated phase is arbitrarily chosen. The corresponding limits for the In concentration are calculated from these values with the help of Eq. (9).

\begin{tabular}{lccr}
\hline Phase & $\frac{[\mathrm{Cu}]}{[\mathrm{Cu}]+[\mathrm{In}]+[\mathrm{Se}]}$, min. & $\frac{[\mathrm{Cu}]}{[\mathrm{Cu}]+[\mathrm{In}]+[\mathrm{Se}]}$, max. & $D_{\text {In, }-3 \mathrm{Cu} / \mathrm{cm}^{2} \mathrm{~s}^{-1}}$ \\
Cu-poor CuInSe & $0.21^{36}$ & $0.248^{36}$ & $1.3 \cdot 10^{-10}$ \\
Cu-saturated CuInSe & $0.248^{36}$ & 0.2485 & $13 \cdot 10^{-10}$ \\
$\left(\mathrm{Cu}_{2}, \mathrm{In}_{2 / 3}\right) \mathrm{Se}$ & $0.6567^{36}$ & $0.6667^{36}$ & $20 \cdot 10^{-10}$ \\
\hline
\end{tabular}

mental observations. Reaction-diffusion modeling has recently proven to be a promising tool for studying Ga gradient formation in three-stage CIGSe growth ${ }^{38}$ or phase formation in sequential CISe growth. ${ }^{39}$

\section{Diffusion and phase boundaries}

The reaction-diffusion modeling is started from a film of $\mathrm{Cu}$-poor $\alpha$-CISe phase. In the $\alpha$-CISe phase, $\mathrm{Cu}$ deficiency is assumed to cause randomly distributed $\mathrm{In}_{\mathrm{Cu}}+2 \mathrm{~V}_{\mathrm{Cu}}$ defect couples. ${ }^{40-42}$ This means that the diffusion of one In atom is directly coupled to diffusion of 3 $\mathrm{Cu}$ atoms in the opposite direction. ${ }^{26}$ Assuming further that the cation diffusion takes place in a rigid Se sublattice, the three-component $\mathrm{Cu}$-In diffusion problem can be reduced to a one-component diffusion problem. Since close to the $\mathrm{CuInSe}_{2}$ stoichiometry the concentration of the defect complexes is dilute, Fickian diffusion can be applied:

$$
\frac{\partial c_{\text {In }}}{\partial t}=-D_{\text {In },-3 \mathrm{Cu}} \frac{\partial c_{\text {In }}}{\partial z},
$$

where $c_{\mathrm{In}}$ and $c_{\mathrm{Cu}}$ are the concentrations of In and $\mathrm{Cu}$ in terms of atoms per volume, $D_{\mathrm{In},-3 \mathrm{Cu}}$ is the diffusion coefficient of coupled $\mathrm{In}-3 \mathrm{Cu}$ diffusion, and $z$ is the vertical distance from the backside of the film. The diffusion coefficient is approximated to be composition independent within one phase, but assumed to be different for different phases. The homogeneity ranges and diffusion coefficients of the phases used as input parameters for the model are listed in Table I. In a Cu-saturated CIGSe film, the In and $\mathrm{Ga}$ interdiffusion has been shown to strongly increase compared to $\mathrm{Cu}$-poor CIGSe, ${ }^{43,44}$ which is believed to be due to $\mathrm{Cu}$-Se precipitations within the CIGSe film. Therefore we introduce a Cu-saturated CISe phase with an increased diffusion coefficient compared to the $\mathrm{Cu}$-poor CISe. This phase may be understood to represent a mixture of near stoichiometric CISe with small $\mathrm{Cu}-\mathrm{Se}$ precipitations at grain boundaries and possibly also within grains. Actually, diffusion in such a situation will not be purely one-dimensional, but it is assumed here that one-dimensional diffusion serves as a fairly good approximation. An even higher diffusivity is assumed for the $\mathrm{Cu}_{2-\delta}$ Se phase with solved $\mathrm{In}_{2} \mathrm{Se}_{3}$ (denoted by $\left(\mathrm{Cu}_{2-\delta}\right)_{1-\mathrm{x}}\left(\mathrm{In}_{2 / 3}\right)_{\mathrm{x}}$ Se or short $\left.\left(\mathrm{Cu}_{2-\delta}, \mathrm{In}_{2 / 3}\right) \mathrm{Se}\right)$. This assumption is based on the fact that $\mathrm{Cu}_{2-\delta}$ Se has a high density of unordered cation vacancies making it a superionic conductor. ${ }^{45}$ (For simplicity, $\delta$ is set to zero in the modeling.) No quantitative data on the diffusion coefficient of coupled $\mathrm{In}-3 \mathrm{Cu}$ diffusion was found in the literature; the values given in Table I where tuned to adjust the model results to our experimental observations as explained further down.

Eq. (8) is solved numerically by an explicit ansatz and by utilizing a simple time discretization as well as a finite volume approach; the film is subdivided into 20- to 40$\mathrm{nm}$ thick sublayers with constant concentrations (see SM for details ${ }^{22}$ ). The $\mathrm{Cu}$ concentration is calculated from the In concentration by assuming that in each sublayer phase equilibrium along the quasi-binary $\mathrm{In}_{2} \mathrm{Se}_{3}-\mathrm{Cu}_{2} \mathrm{Se}$ line $^{36}$ is fulfilled: ${ }^{22}$

$$
c_{\mathrm{Cu}}=2 c_{\mathrm{Se}}-3 c_{\mathrm{In}},
$$

where the Se concentration $c_{\mathrm{Se}}$ is approximated to be constant with $c_{\mathrm{Se}}=20.3$ atoms $/ \mathrm{nm}^{3}$ (which assumes $8 \mathrm{Se}$ atoms per unit cell with a unit cell volume of $0.394 \mathrm{~nm}^{3}$ as extracted from the in-situ measured $\mathrm{CuInSe}_{2}$ peak positions at $530{ }^{\circ} \mathrm{C}$ near the $\mathrm{Cu}$ saturation point).

\section{Cu-Se deposition and film growth}

After each time step $\Delta t$ a certain amount of $\mathrm{Cu}_{2}$ Se is added to the surface of the film, defined by the $\mathrm{Cu}$ flux of the $\mathrm{Cu}$ evaporation source $\Phi_{\mathrm{Cu}}=6.92$ atoms nm ${ }^{-2} \mathrm{~s}^{-1}=$ $2 \Phi_{\mathrm{Se}}{ }^{22}$ (In the CISe deposition process Se is offered in excess - hence the $\mathrm{Cu}_{2}$ Se deposition rate is governed by the $\mathrm{Cu}$ rate.) This leads to a lowering of the In concentration at the surface and consequently to diffusion of In from the bulk towards the surface according to Eq. (8) (Fig. 4a). When the In concentration reaches the lower limit for $\mathrm{Cu}$-poor CISe and hence the upper limit given for the $\mathrm{Cu}$-saturated CISe phase, the higher diffusion coefficient assumed for $\mathrm{Cu}$-saturated CISe (Table I) leads to a flattened gradient (Fig. 4b). The evolution of the thickness of the Cu-saturated part of the film is plotted in Fig. $4 d$. 


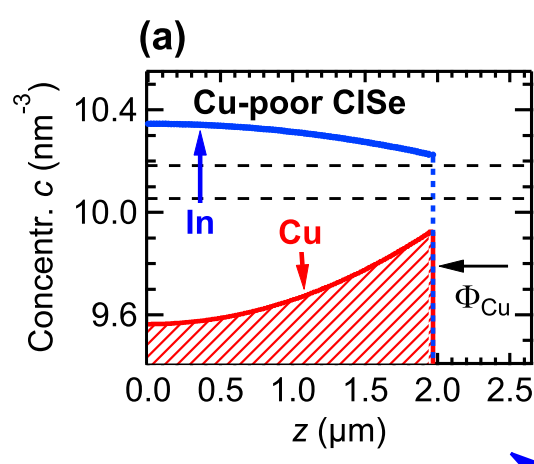

(b)

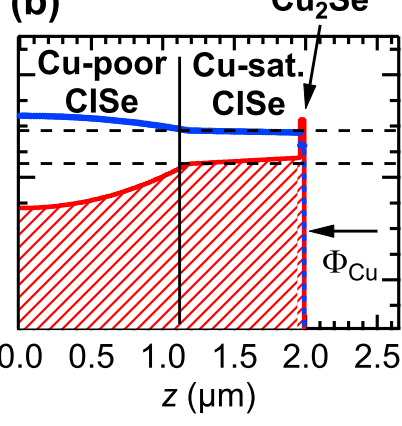

(c)

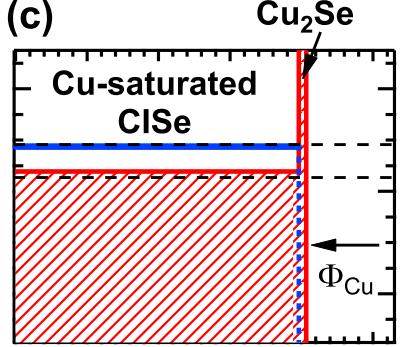

0.00 .51 .01 .52 .025

(d)
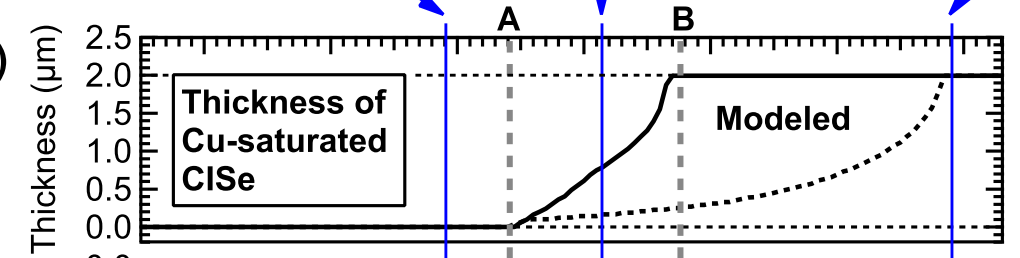

(e)

(f)

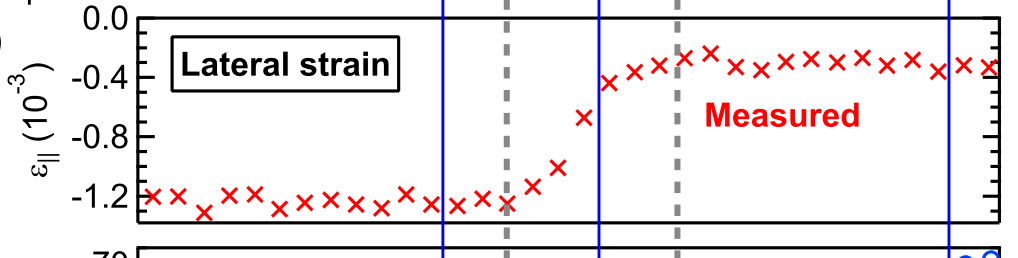

(f)

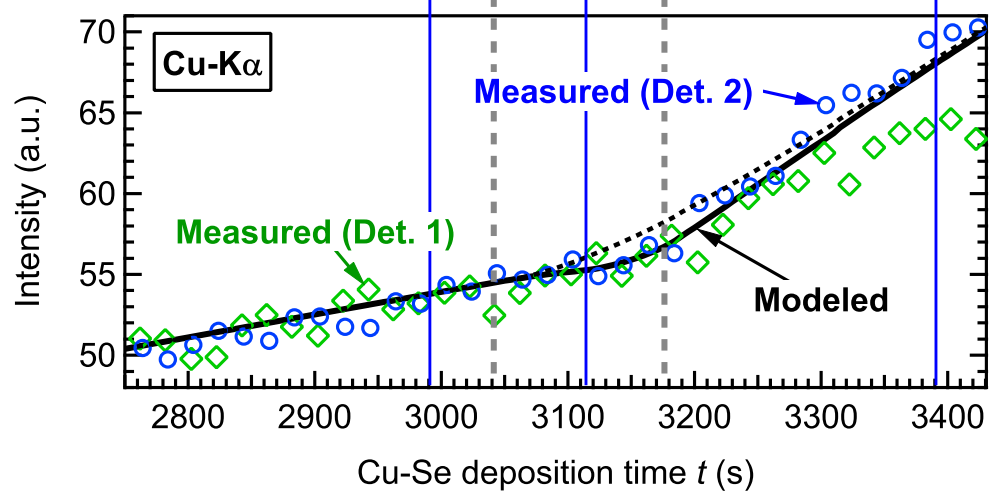

Figure 4. Comparison of modeled and measured real-time data at the $\mathrm{Cu}$-poor to $\mathrm{Cu}$-rich transition during $\mathrm{Cu}-\mathrm{Se}$ deposition onto a Cu-In-Se film. (a-c) $\mathrm{Cu}$ and In concentration (in atoms $/ \mathrm{nm}^{3}$ ) plotted against the distance $z$ from the backside of the film as resulting from numerical reaction-diffusion modeling. At the surface at $z \approx 2 \mu \mathrm{m}, \mathrm{Cu}_{2} \mathrm{Se}$ is added to the film at each time step determined by the $\mathrm{Cu}$ evaporation rate of the process presented in Fig. 3. The horizontal dashed lines mark the highest $\mathrm{Cu}$ and the lowest In concentration for the $\alpha$-CISe homogeneity range according to Gödecke et al. (see Table I). ${ }^{36}$ (d) Propagation of the thickness of the Cu-saturated part of the film as resulting from the reaction-diffusion modeling. (e) Evolution of the strain relaxation as extracted from $3 \mathrm{~b}$ (red crosses). (f) Evolution of measured and simulated Cu-K $\alpha$ fluorescence intensities. (d-f) The vertical dashed lines labeled A and B correspond to the vertical lines in Fig. 3. The black dotted lines represent modeling results where the diffusion coefficient for $\mathrm{Cu}$-saturated CISe is set equal to that of $\mathrm{Cu}$-poor CISe.

\section{Cu-Se segregation}

Once the In concentration at the surface falls below the homogeneity range for CISe (i.e. $[\mathrm{Cu}] /([\mathrm{Cu}]+[\mathrm{In}]+[\mathrm{Se}])$ exceeds the max. value for CISe in Table I), segregation of $\left(\mathrm{Cu}_{2}, \mathrm{In}_{2 / 3}\right)$ Se takes place (Fig. $4 \mathrm{~b}$ and c). (See SM for details ${ }^{22}$.) As long as the back side of the film is still $\mathrm{Cu}$-poor, the main share of the $\mathrm{Cu}$ deposited to the film surface diffuses into the film - while In diffuses out, forming additional CISe at the surface by consuming part of the deposited $\mathrm{Cu}_{2}$ Se. A thin layer of $\left(\mathrm{Cu}_{2}, \mathrm{In}_{2 / 3}\right)$ Se may already form at the surface if the rate of $\mathrm{Cu}$ indiffusion falls below the rate of $\mathrm{Cu}$ deposition (Fig. 4b). This early formation of $\left(\mathrm{Cu}_{2}, \mathrm{In}_{2 / 3}\right)$ Se at the surface, which is not detectable by XRF, may explain the rise of the LLS signal before the $\mathrm{Cu}-\mathrm{K} \alpha$ intensity kink (Fig. 3e,f). Once the complete film is saturated with $\mathrm{Cu}$ (point $\mathrm{B}$ ), $\mathrm{Cu}$ dif- 
fusion into the film stops and all further deposited $\mathrm{Cu}_{2} \mathrm{Se}$ segregates at the film surface as $\left(\mathrm{Cu}_{2}, \mathrm{In}_{2 / 3}\right) \mathrm{Se}$ - i.e. the growth rate of $\left(\mathrm{Cu}_{2}, \mathrm{In}_{2 / 3}\right)$ Se at the surface reaches its maximum. Upon further $\mathrm{Cu}_{2}$ Se deposition the solubility of $\mathrm{In}_{2} \mathrm{Se}_{3}$ in $\mathrm{Cu}_{2}$ Se leads to a slow decomposition of CISe at the interface between CISe and $\left(\mathrm{Cu}_{2}, \mathrm{In}_{2 / 3}\right) \mathrm{Se}$.

\section{Comparison between model and measurement}

To quantitatively compare the model to the real-time experiment presented above, we simulate the $\mathrm{Cu}-\mathrm{K} \alpha$ fluorescence signal intensity resulting from the model as function of time (for details on the fluorescence simulation see Ref. $\left.{ }^{34}\right)$. The simulated and measured evolution of the $\mathrm{Cu}-\mathrm{K} \alpha$ intensity are plotted in Fig. 4e. The diffusion coefficient $D_{\mathrm{In},-3 \mathrm{Cu}}$ was adjusted such that $\mathrm{Cu}$-saturation at the surface of the CISe film matches the start of domain growth and stress relaxation as extracted from the experimental data (Fig. 3c). It can be clearly seen in Fig. 4 that the reaction-diffusion model reproduces the delay between the onset of $\mathrm{Cu}$ saturation at the CISe surface (point A) and the kink of $\mathrm{Cu}-\mathrm{K} \alpha$ intensity slope (point B) - and thus provides an explanation for the delay between the onset of recrystallization and the onset of $\mathrm{Cu}$-Se segregation at the surface. We note that the increased $\mathrm{Cu}$ diffusivity assumed for the $\mathrm{Cu}$-saturated part of the film compared to the $\mathrm{Cu}$-poor CISe (Table I) is needed to obtain a good match between the experimental data and the model. Setting the diffusion coefficient of the $\mathrm{Cu}$-saturated CISe phase equal to that of the $\mathrm{Cu}$ poor CISe phase leads only to a small deviation of the modeled evolution $\mathrm{Cu}-\mathrm{K} \alpha$ signal (dotted line in Fig. 4f) from the measured, but the propagation of $\mathrm{Cu}$-saturation through the film takes much longer (dotted line in Fig. 4d) than the experimentally observed recrystallization, which stops at point B.

It is emphasized that if the $\mathrm{Cu}$ flux is stopped at the time presented by Fig. $4 \mathrm{~b}$, the $\mathrm{Cu}$ and In distributions homogenize, resulting in an overall slightly $\mathrm{Cu}$-poor CISe film with $[\mathrm{Cu}] /([\mathrm{Cu}]+[\mathrm{In}]+[\mathrm{Se}])<0.248$. Despite the fact that the overall composition of this film has never been $\mathrm{Cu}$-rich with $[\mathrm{Cu}] /([\mathrm{Cu}]+[\mathrm{In}]+[\mathrm{Se}])>0.248$, the surface near part of the film recrystallized due to an temporary
Cu-saturated composition.

\section{CONCLUSION}

In conclusion we have shown by a combination of real-time diffraction and fluorescence analysis that rapid relaxation of compressive stress, which builds up during incorporation of $\mathrm{Cu}$ into the $\mathrm{Cu}$-poor $\mathrm{Cu}-\mathrm{In}-\mathrm{Se}$ film, takes place shortly before the onset of $\mathrm{Cu}$-Se segregation at the surface. Furthermore, stress relaxation precisely coincides with an increase of domain size and change of texture. We find that compressive stress can act as an additional driving force for domain growth and recrystallization at the transition from $\mathrm{Cu}$-poor to $\mathrm{Cu}$-rich $\mathrm{CuInSe}_{2}$. The compressive stress formation due to lattice expansion during increasing $\mathrm{Cu}$ concentration is a unique feature of the three-stage process, and is absent in the two-stage process featuring only a $\mathrm{Cu}$-rich $\rightarrow \mathrm{Cu}$-poor transition. Hence, in the latter the absence of the additional driving force for recrystallization may contribute to an explanation for the lower performance of the two-stage process compared to the three-stage process. Moreover, our results reveal that partial recrystallization can be achieved even without reaching an overall $\mathrm{Cu}$-saturated film composition and hence without the necessity of a final In-Ga-Se deposition (3rd stage) for the removal of excess $\mathrm{Cu}$-Se at the surface, thus conserving the unspoiled recrystallized film surface. This finding may point towards a new process route for the fabrication of CIGSe films with high-quality surface properties.

\section{ACKNOWLEDGMENTS}

This work was partly funded through the Bundesministerium für Bildung und Forschung (GRACIS, ID 03SF0359D), through the Helmholtz Association, Virtual Institute VH-VI-520, and through the European Metrology Research Programme (EMRP) Project ENG53 ThinErgy. The EMRP is jointly funded by the EMRP participating countries within EURAMET and the European Union. Special thanks go to Guido Wagener, Tim Münchenberg, and Lars Steinkopf for technical support.
* roland.mainz@helmholtz-berlin.de

1 A. Chirila, P. Reinhard, F. Pianezzi, P. Bloesch, A. R. Uhl, C. Fella, L. Kranz, D. Keller, C. Gretener, H. Hagendorfer, D. Jaeger, R. Erni, S. Nishiwaki, S. Buecheler, and A. N. Tiwari, Nat. Mater. 12, 1107 (2013).

2 P. Jackson, D. Hariskos, R. Wuerz, W. Wischmann, and M. Powalla, Phys. Status Solidi RRL 8, 219 (2014).

${ }^{3}$ R. Caballero, C. Kaufmann, V. Efimova, T. Rissom, V. Hoffmann, and H. Schock, Prog. Photovolt: Res. Appl.
21, 30 (2013).

4 A. M. Gabor, J. R. Tuttle, D. S. Albin, M. A. Contreras, R. Noufi, and A. M. Hermann, Appl. Phys. Lett. 65, 198 (1994).

5 M. Contreras, J. Tuttle, A. Gabor, A. Tennant, K. Ramanathan, S. Asher, A. Franz, J. Keane, L. Wang, J. Scofield, and R. Noufi, in Photovoltaic Energy Conversion, 1994., Conference Record of the Twenty Fourth IEEE Photovoltaic Specialists Conference - 1994, 1994 
IEEE First World Conference on, Vol. 1 (1994) pp. 6875.

${ }^{6}$ R. A. Mickelsen and W. S. Chen, in 16th Photovoltaic Specialists Conference (1982) pp. 781-785.

7 T. Schlenker, M. L. Valero, H. Schock, and J. Werner, J. Cryst. Growth 264, 178 (2004).

8 N. Barreau, T. Painchaud, F. Couzinié-Devy, L. Arzel, and J. Kessler, Acta Mater. 58, 5572 (2010).

9 H. Rodriguez-Alvarez, R. Mainz, B. Marsen, D. Abou-Ras, and H. W. Schock, J. Appl. Cryst. 43, 1053 (2010).

10 H. Rodriguez-Alvarez, N. Barreau, C. Kaufmann, A. Weber, M. Klaus, T. Painchaud, H.-W. Schock, and R. Mainz, Acta Mater. 61, 4347 (2013).

11 L. Gütay, D. Regesch, J. K. Larsen, Y. Aida, V. Depredurand, and S. Siebentritt, Appl. Phys. Lett. 99, 151912 (2011).

12 J. W. Shin and E. Chason, Phys. Rev. Lett. 103, 056102 (2009).

13 T. J. Rupert, D. S. Gianola, Y. Gan, and K. J. Hemker, Science 326, 1686 (2009).

14 R. Gupta, A. Gupta, W. Leitenberger, and R. Rüffer, Phys. Rev. B 85, 075401 (2012).

15 C.-W. Pao, S. M. Foiles, E. B. Webb, D. J. Srolovitz, and J. A. Floro, Phys. Rev. Lett. 99, 036102 (2007).

16 T. Frolov, W. Boettinger, and Y. Mishin, Acta Materialia 58, 5471 (2010).

17 C. V. Thompson and R. Carel, J. Mech. Phys. Solids 44, 657 (1996).

18 I. M. Kötschau and H. W. Schock, J. Phys. Chem. Solids 64, 1559 (2003).

19 H. Rodriguez-Alvarez, A. Weber, J. Lauche, C. A. Kaufmann, T. Rissom, D. Greiner, M. Klaus, T. Unold, C. Genzel, H.-W. Schock, and R. Mainz, Adv. Energy Mater. 3, 1381 (2013).

20 C. Genzel, I. A. Denks, R. Coelho, D. Thomas, R. Mainz, D. Apel, and M. Klaus, J. Strain Anal. Eng. Des. 46, 615 (2011).

21 R. Scheer, A. Perez-Rodriguez, and W. K. Metzger, Prog. Photovolt: Res. Appl. 18, 467 (2010).

${ }^{22}$ See Supplemental Material at http://aps.org for the evolution of strain, Cu fluorescence, and phase formation during second stage of the CuInSe2 deposition; comparison of lattice spacings, peak broadening, and domain size of $\mathrm{Cu}$ In-Se reflexes; $x$-ray information depth for various photon energies; diffuse and direct light scattering; calculation of relaxed lattice spacing and Poisson's ratio; details on reaction-diffusion modeling. APS will create the link at the time of publishing.

${ }^{23}$ L. D. Landau and E. M. Lifshitz, Theory of Elasticity (Pergamon, Oxford, 1986).

24 M. Birkholz, Thin film analysis by X-ray scattering (John Wiley \& Sons, Weinheim, 2006).

25 N. Rega, Photolumineszenz von epitaktischen $\mathrm{Cu}(\mathrm{In}, \mathrm{Ga}) \mathrm{Se}_{2}-$ Schichten, Ph.D. thesis, Freie Universität Berlin (2004).
${ }^{26}$ A. M. Gabor, J. R. Tuttle, M. H. Bode, A. Franz, A. L. Tennant, M. A. Contreras, R. Noufi, D. G. Jensen, and A. M. Hermann, Sol. Energy Mater. Sol. Cells 41/42, 247 (1996).

27 D. Abou-Ras, B. Schaffer, M. Schaffer, S. S. Schmidt, R. Caballero, and T. Unold, Phys. Rev. Lett. 108, 075502 (2012).

28 S. S. Schmidt, D. Abou-Ras, S. Sadewasser, W. Yin, C. Feng, and Y. Yan, Phys. Rev. Lett. 109, 095506 (2012).

29 A. P. Kumar and K. Reddy, Thin Solid Films 304, 365 (1997).

30 T. Tinoco, A. Polian, D. Gómez, and J. P. Itié, phys. stat. sol. (b) 198, 433 (1996).

31 R. Fouret, B. Hennion, J. Gonzalez, and S. M. Wasim, Phys. Rev. B 47, 8269 (1993).

${ }^{32}$ R. D. Doherty, D. A. Hughes, F. J. Humphreys, J. J. Jonas, D. Juul Jensen, M. E. Kassner, W. E. King, T. R. McNelley, H. J. McQueen, and A. D. Rollett, Materials Science and Engineering A 238, 219 (1997).

33 R. Klenk, T. Walter, H.-W. Schock, and D. Cahen, Adv. Mater. 5, 114 (1993).

34 R. Mainz and R. Klenk, J. Appl. Phys. 109, 123515 (2011).

35 P. Pradhan, P. Aryal, A.-R. Ibdah, K. Aryal, J. Li, N. Podraza, S. Marsillac, and R. Collins, in Photovoltaic Specialist Conference (PVSC), 2014 IEEE 40th (2014) pp. 2060-2065.

${ }^{36}$ T. Gödecke, T. Haalboom, and F. Ernst, Z. Metallkd. 91, 622 (2000).

37 V. Ranjan, K. Aryal, S. Little, Y. Erkaya, G. Rajan, P. Boland, D. Attygalle, P. Aryal, P. Pradhan, R. Collins, and S. Marsillac, in Photovoltaic Specialists Conference (PVSC), 2012 38th IEEE (2012) pp. 000452-000454.

38 H. Rodriguez-Alvarez, R. Mainz, and S. Sadewasser, J. Appl. Phys. 115, 204913 (2014).

39 A. Zweschke and P. J. Wellmann, Thin Solid Films 582, 397 (2015), e-MRS 2014 Spring Meeting, Symposium A, Thin-Film Chalcogenide Photovoltaic Materials.

40 S. B. Zhang, S.-H. Wei, and A. Zunger, Phys. Rev. Lett. 78, 4059 (1997).

41 S. Lehmann, D. F. Marron, M. Leon, R. Feyerherm, E. Dudzik, E. J. Friedrich, M. Tovar, Y. Tomm, C. Wolf, S. Schorr, T. Schedel-Niedrig, M. C. Lux-Steiner, and J. M. Merino, J. Appl. Phys. 109, 013518 (2011).

42 C. Stephan, S. Schorr, M. Tovar, and H.-W. Schock, Applied Physics Letters 98, 091906 (2011).

43 O. Lundberg, J. Lu, A. Rockett, M. Edoff, and L. Stolt, J. Phys. Chem. Solids 64, 1499 (2003).

44 T. Rissom, R. Mainz, C. A. Kaufmann, R. Caballero, V. Efimova, V. Hoffmann, and H.-W. Schock, Sol. Energy Mater. Sol. Cells 95, 250 (2011).

${ }^{45}$ H. Liu, X. Shi, F. Xu, L. Zhang, W. Zhang, L. Chen, Q. Li, C. Uher, T. Day, and G. J. Snyder, Nat. Mater. 11, 422 (2012). 